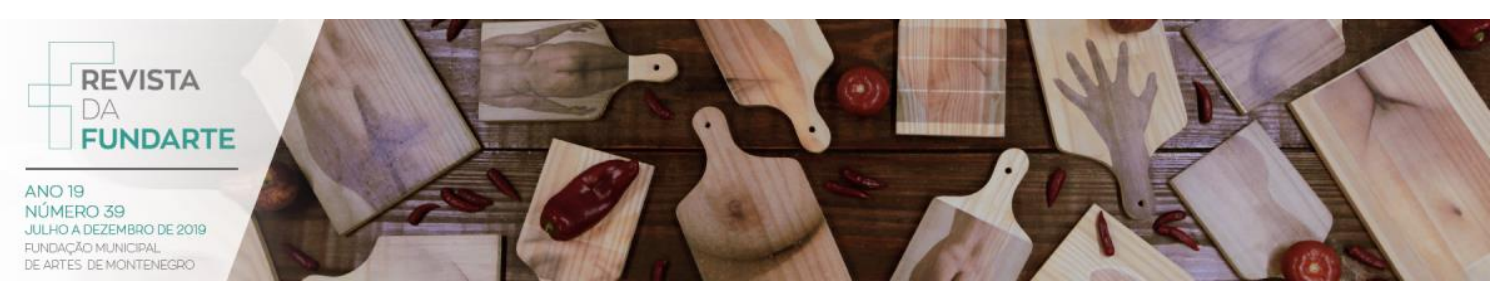

\title{
FORMAÇÃO E PROPOSTAS PEDAGÓGICAS PARA O ENSINO DA DANÇA NO BALÉ POPULAR DO TOCANTINS
}

Webiston da Silva Gloria

Diego Ebling do Nascimento

GLORIA, Webiston da Silva; NASCIMENTO, Diego Ebling do. Formação e propostas pedagógicas para o ensino da dança no balé popular do Tocantins. Revista da FUNDARTE. Montenegro, p.89-104, ano 19, no 39, julho/dezembro de 2019.

Disponível em: http://.seer.fundarte.rs.gov.br/index.php/RevistadaFundarte/index> 20 de dezembro de 2019. 


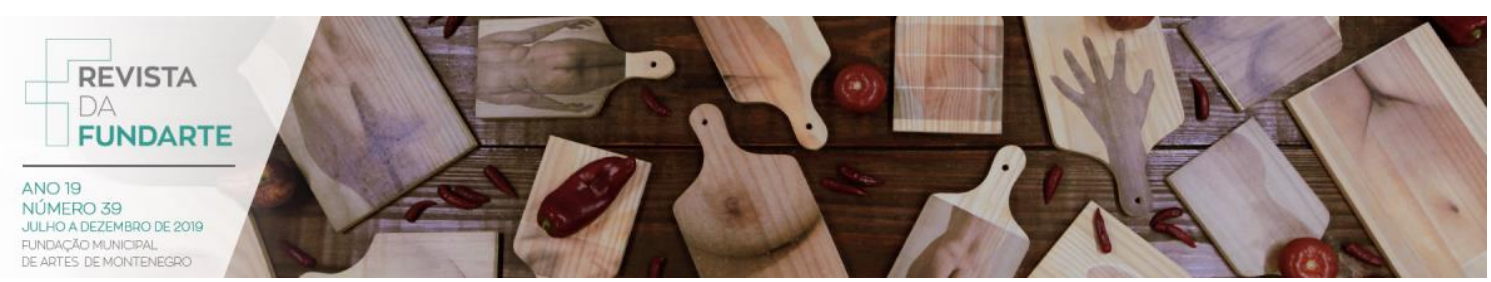

\title{
FORMAÇÃO E PROPOSTAS PEDAGÓGICAS PARA O ENSINO DA DANÇA NO BALÉ POPULAR DO TOCANTINS
}

Webiston da Silva Gloria ${ }^{1}$

Diego Ebling do Nascimento 2

\begin{abstract}
Resumo: O Balé Popular do Tocantins é um grupo de dança que vem realizando diversos trabalhos artísticos dentro das escolas estaduais de Palmas/TO. O objetivo deste estudo é investigar a formação dos professores e as metodologias utilizadas para o ensino da dança no BPT. Foram realizadas entrevistas semiestruturadas com os docentes do projeto. Como resultado percebemos que todos os professores tiveram contato com a dança em suas formações acadêmicas e investiram em sua formação como professores(as) e artistas. Também observamos que o trabalho no BPT é fisicamente desgastante, porém os resultados, aos olhos dos professores, são muito positivos. Concluímos que o BPT é uma oportunidade de profissionalização gratuita e de qualidade na área da dança.
\end{abstract}

Palavras-Chave: Formação em dança; Metodologia de ensino da dança; Dança na escola.

\section{TRAINING AND PEDAGOGICAL PROPOSALS FOR THE TEACHING OF DANCE IN THE POPULAR BALLET OF TOCANTINS}

ABSTRACT: The Popular Ballet of Tocantins is a dance group that has been performing various artistic works within the state schools of Palmas/TO. The objective of this study is to investigate teacher training and the methodologies used for teaching dance in BPT. We conducted semistructured interviews with the project teachers. As a result, we realized that all teachers had contact with dance in their academic formations and invested in teacher and artist training. We also observed that the work in the BPT is physically exhausting, but the results, in the eyes of the teachers, are very positive. We conclude that the BPT is an opportunity for free professionalization and quality in the dance area.

Keywords: Balé Popular do Tocantins; Training in dance; Teaching methodology.

\section{CONSIDERAÇÕES INICIAIS}

O Balé Popular do Tocantins (BPT) é um projeto extracurricular de dança, aberto à comunidade, que é desenvolvido em Palmas/TO, nas escolas estaduais. Teve início em 2013 e atualmente é considerada uma das maiores companhias de

\footnotetext{
${ }^{1}$ Licenciado em Educação Física pela Universidade Federal do Tocantins. Tem experiência na área da dança e das lutas.

2 Diego Ebling do Nascimento é professor, pesquisador e extensionista em Dança e Educação Física da Universidade Federal do Tocantins. Doutorando em Educação pela Universidade de Santa Cruz do Sul (Unisc); Mestre e graduado em Educação Física pela Universidade Federal de Pelotas (UFPel). Especialista em Dança e Consciência Corporal pela Universidade Gama Filho (UGF); em Artes Híbridas pela Universidade Tecnológica Federal do Paraná (UTFPR); e em Docência do Ensino Superior pelo Instituto Tocantinense de Ensino Superior e Pesquisa (ITOP).
}

GLORIA, Webiston da Silva; NASCIMENTO, Diego Ebling do. Formação e propostas pedagógicas para o ensino da dança no balé popular do Tocantins. Revista da FUNDARTE. Montenegro, p.89-104, ano 19, no 39, julho/dezembro de 2019.

Disponível em: http://.seer.fundarte.rs.gov.br/index.php/RevistadaFundarte/index $>20$ de dezembro de 2019. 


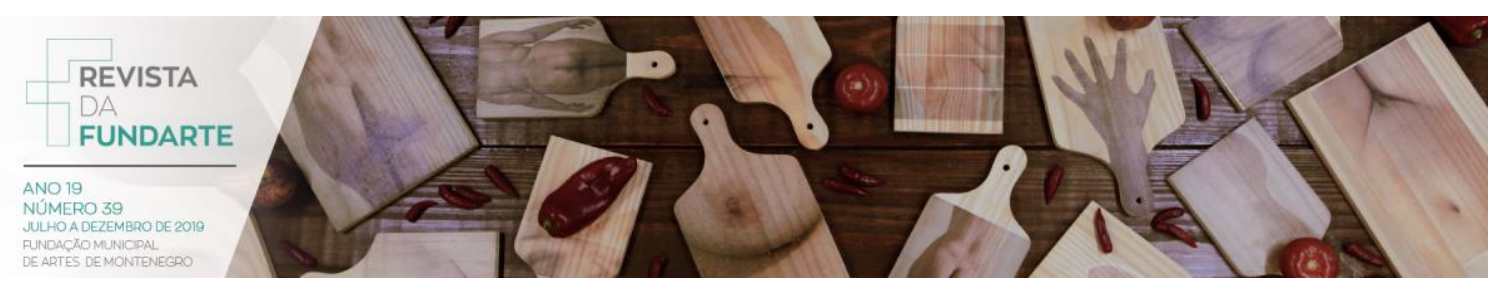

dança do estado. No ano de 2017 atendia aproximadamente 200 alunos, tendo participado de diversos festivais nacionais e internacionais (DE PINHO; SOMMER; MARQUES, 2017).

O crescimento do BPT é notório, em apenas um ano, o número de atendimentos dobrou, passando para 400 alunos atendidos entre crianças, jovens e adultos, em sua maioria da rede pública. O BPT conta, hoje, com 11 professores de dança e atende cinco escolas estaduais.

Além de proporcionar vivências e experiências por meio do ensino da dança no Tocantins, o BPT também tem um papel importante na formação de profissionais que atuam como professores de dança na região, contribuindo com a disseminação da dança cênica pelo estado, principalmente na capital - Palmas/TO (DE PINHO; SOMMER; MARQUES, 2017).

Essa pesquisa se propõe a investigar qual a formação dos professores do BPT e quais metodologias são utilizadas para o ensino da dança no projeto.

De acordo com Nunes (2001, p. 28), "as pesquisas sobre formação de professores têm destacado a importância de se analisar a questão da prática pedagógica como algo relevante, opondo-se assim às abordagens que procuravam separar formação e prática cotidiana".

No que tange a metodologia para o ensino da dança, Marques (2003) propõe a construção de caminhos em que os professores possam trabalhar os conteúdos da dança, articulando-os com os conceitos de corpo, dança e educação. Além disso, a autora incentiva a relação professor-aluno de forma a dialogar com necessidades do mundo contemporâneo. Nesse sentido, há autores que se dedicaram a pensar o universo dos estudos metodológicos da dança (MARQUES, 2003; MARTINELLI; BARBATO; MITJANS, 2003; CORRÊA; MARTINS; SANTOS, 2017).

Para justificar o trabalho partimos de dois pressupostos: o primeiro é que a formação docente e artística dos professores do BPT contribui significativamente para as escolhas dos fazeres pedagógicos atuais. O segundo é que os professores do BPT têm formações, saberes e modos de pensar/fazer dança diferentes que, também, se relacionam diretamente à sua formação acadêmica e artística.

GLORIA, Webiston da Silva; NASCIMENTO, Diego Ebling do. Formação e propostas pedagógicas para o ensino da dança no balé popular do Tocantins. Revista da FUNDARTE. Montenegro, p.89-104, ano 19, no 39, julho/dezembro de 2019.

Disponível em: http://.seer.fundarte.rs.gov.br/index.php/RevistadaFundarte/index $>20$ de dezembro de 2019. 


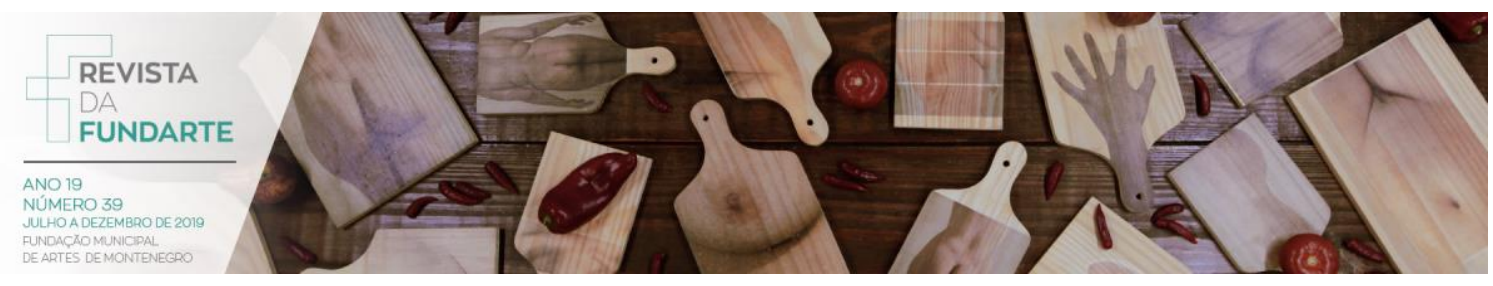

Nesse sentido a identificação, sistematização e reflexão sobre a formação docente e as estratégicas artístico-metodológicas baseadas nesses dois pressupostos pode contribuir para aprimorar a qualidade do ensino da dança no projeto e em outros espaços que tenham a dança como principal prática. Além disso, conhecer a trajetória e as metodologias utilizadas pelos professores do BPT é uma forma de entender como se organiza o projeto e esse fato pode contribuir para a inserção da dança nas escolas de modo a estimular e promover outras iniciativas como esta.

\section{METODOLOGIA}

Foi realizada uma pesquisa qualitativa que teve como procedimento entrevistas semiestruturadas (TRIVIÑOS, 1987), no sentido de compreender como acontecem as propostas pedagógicas e metodológicas para o ensino da dança no projeto BPT.

Os critérios de inclusão para os participantes foram: a) ser professores do BPT; e b) estarem atuando no projeto. Os critérios de exclusão foram aplicados quando: a) os professores não aceitaram participar da pesquisa; b) estavam afastados do projeto por quaisquer motivos; e/ou c) não assinaram o Termo de Consentimento Livre e Esclarecido (TCLE) da pesquisa.

O estudo foi composto por oito professores do BPT, os quais atuam em escolas na região norte, centro e sul da cidade de Palmas/Tocantins. A coleta de dados aconteceu em dezembro de 2018, após a última reunião do BPT. Todos os professores presentes aceitaram participar da pesquisa.

Para manter a descrição da identidade dos professores utilizaremos nomes de passos do ballet clássico, visto que é a técnica de dança mais utilizada no BPT.

A análise de dados teve inspiração na análise de conteúdo. Após a realização das entrevistas, as respostas dos professores foram distribuídas em tabelas de forma descritiva para podermos extrair as categorias. As respostas que não respondiam as perguntas propostas foram para a tabela, como "indefinido". para o ensino da dança no balé popular do Tocantins. Revista da FUNDARTE. Montenegro, p.89-104, ano 19, no 39, julho/dezembro de 2019.

Disponível em: http://.seer.fundarte.rs.gov.br/index.php/RevistadaFundarte/index $>20$ de dezembro de 2019. 


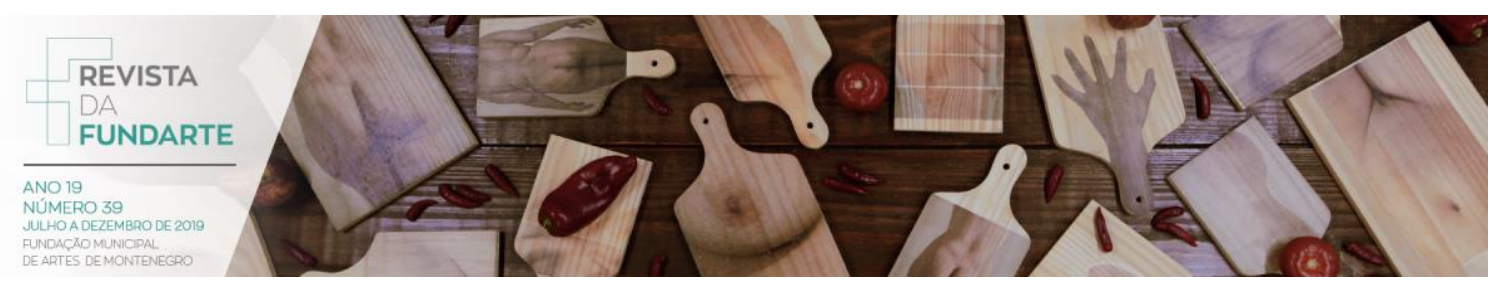

RESULTADOS E DISCUSSÕES

O corpo docente do BPT é bastante diversificado no que se refere ao tempo de atuação no projeto. No entanto, nossa investigação permitiu que conversássemos com professores que recém entraram e com professores que fazem parte, desde a fundação do BPT. O quadro 1 apresenta essa diversidade de tempo.

\begin{tabular}{|c|c|}
\hline Professores & Tempo de Projeto \\
\hline Arabesque & 72 meses até a data da pesquisa \\
\hline Cambré & 72 meses até a data da pesquisa \\
\hline Chassé & 72 meses até a data da pesquisa \\
\hline Ecarté & 72 meses até a data da pesquisa \\
\hline Tendu & 72 meses até a data da pesquisa \\
\hline Frappé & 11 meses até a data da pesquisa \\
\hline Jeté & 11 meses até a data da pesquisa \\
\hline Plié & 03 meses até a data da pesquisa \\
\hline
\end{tabular}

Quadro 1 - Tempo de trabalho no projeto. Fonte: Elaborada pelos autores

\section{A FORMAÇÃO DOS PROFESSORES DE DANÇA DO BPT}

Os professores do BPT têm formações diferentes, no entanto identificamos que a maioria é formada em Educação Física, como podemos perceber no quadro 2. Esse é um reflexo da ausência de cursos superiores de dança na região. Nesse sentido, percebemos a importância do conteúdo dança na grade curricular da formação em Educação Física, tanto nos cursos de formação de professores como na formação de bacharéis. Entretanto, observamos que todos os professores, além de suas formações acadêmicas, estudaram dança em espaços não formais de educação, por meio de bolsa de estudos em academias especializadas, em cursos e workshops.

GLORIA, Webiston da Silva; NASCIMENTO, Diego Ebling do. Formação e propostas pedagógicas para o ensino da dança no balé popular do Tocantins. Revista da FUNDARTE. Montenegro, p.89-104, ano 19, no 39, julho/dezembro de 2019.

Disponível em: http://.seer.fundarte.rs.gov.br/index.php/RevistadaFundarte/index $>20$ de dezembro de 2019. 


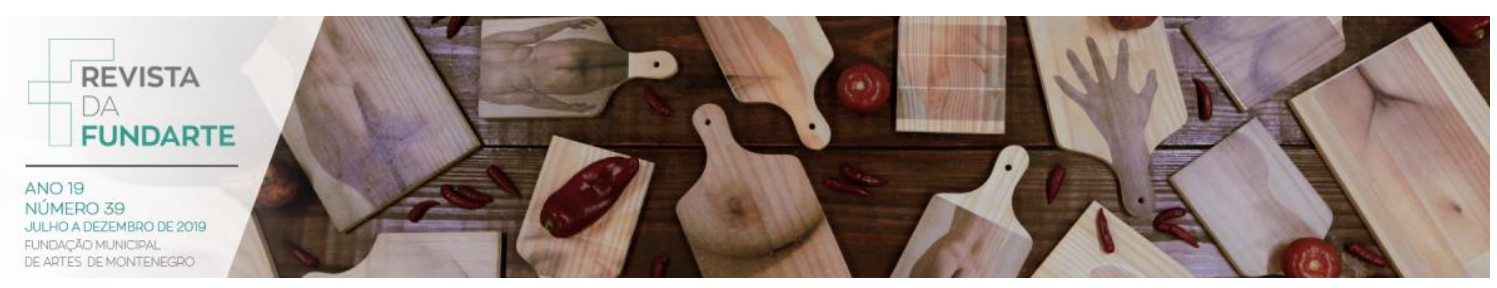

\begin{tabular}{|c|c|c|c|c|}
\hline Professor & Início & $\begin{array}{l}\text { Formação } \\
\text { Acadêmica }\end{array}$ & $\begin{array}{l}\text { Formação em } \\
\text { espaços não } \\
\text { formais de } \\
\text { ensino }\end{array}$ & $\begin{array}{l}\text { Complemento de } \\
\text { formação }\end{array}$ \\
\hline Plié & $\begin{array}{c}\mathrm{Na} \\
\text { adolescência }\end{array}$ & $\begin{array}{l}\text { Educação } \\
\text { Física }\end{array}$ & $\begin{array}{l}\text { Bolsa de estudo } \\
\text { em ballet }\end{array}$ & Cursos de ballet \\
\hline Chassé & $\begin{array}{c}\mathrm{Na} \\
\text { adolescência }\end{array}$ & $\begin{array}{l}\text { Educação } \\
\text { Física }\end{array}$ & $\begin{array}{l}\text { Aulas de dança } \\
\text { de salão na } \\
\text { adolescência; } \\
\text { jazz e ballet; } \\
\text { competições. }\end{array}$ & $\begin{array}{c}\text { Dança de salão; } \\
\text { cursos de dança } \\
\text { fora do estado do } \\
\text { Tocantins. }\end{array}$ \\
\hline Tendu & $\begin{array}{l}\mathrm{Na} \\
\text { graduação }\end{array}$ & $\begin{array}{l}\text { Educação } \\
\text { Física }\end{array}$ & $\begin{array}{c}\text { Aulas de ballet; } \\
\text { jazz e dança de } \\
\text { salão. }\end{array}$ & $\begin{array}{l}\text { Cursos; workshops; } \\
\text { formação de } \\
\text { professores e } \\
\text { ensino da dança. }\end{array}$ \\
\hline Cambré & $\begin{array}{l}\mathrm{Na} \\
\text { graduação }\end{array}$ & $\begin{array}{l}\text { Educação } \\
\text { Física }\end{array}$ & $\begin{array}{c}\text { Dança criativa; } \\
\text { danças } \\
\text { populares; ballet; } \\
\text { jazz e dança de } \\
\text { salão. }\end{array}$ & $\begin{array}{c}\text { Pós graduação em } \\
\text { dança e consciência } \\
\text { corporal. }\end{array}$ \\
\hline Jeté & Na infância & Dança & $\begin{array}{c}\text { Bolsa de Estudos } \\
\text { em escola de } \\
\text { formação em } \\
\text { dança. }\end{array}$ & $\begin{array}{c}\text { Prática docente em } \\
\text { projetos sociais e } \\
\text { escolas }\end{array}$ \\
\hline Frappé & $\begin{array}{l}\text { Não soube } \\
\text { informar }\end{array}$ & Teatro & Prática de ballet & $\begin{array}{c}\text { Cursos nacionais e } \\
\text { internacionais }\end{array}$ \\
\hline Ecarté & $\begin{array}{c}\mathrm{Na} \\
\text { adolescência }\end{array}$ & $\begin{array}{l}\text { Educação } \\
\text { Física }\end{array}$ & Prática de ballet & Cursos nacionais \\
\hline Arabesque & $\begin{array}{c}\mathrm{Na} \\
\text { adolescência }\end{array}$ & $\begin{array}{l}\text { Educação } \\
\text { Física } \\
\end{array}$ & $\begin{array}{c}\text { Prática de ballet } \\
\text { e jazz }\end{array}$ & Cursos nacionais \\
\hline
\end{tabular}

Quadro 2 - Formações dos professores. Fonte: Elaborada pelos autores

Percebemos que as formações dos professores do BPT se deram por meio de suas histórias de vida e os saberes que foram adquiridos ao longo dela. Muitos dos professores estavam envolvidos com a dança desde muito novos, e esse fato pode ter contribuído significativamente para que os mesmos se tornassem professores de dança. A formação docente se deu por meio de suas experiências, para o ensino da dança no balé popular do Tocantins. Revista da FUNDARTE. Montenegro, p.89-104, ano 19, no 39, julho/dezembro de 2019.

Disponível em: http://.seer.fundarte.rs.gov.br/index.php/RevistadaFundarte/index $>20$ de dezembro de 2019. 


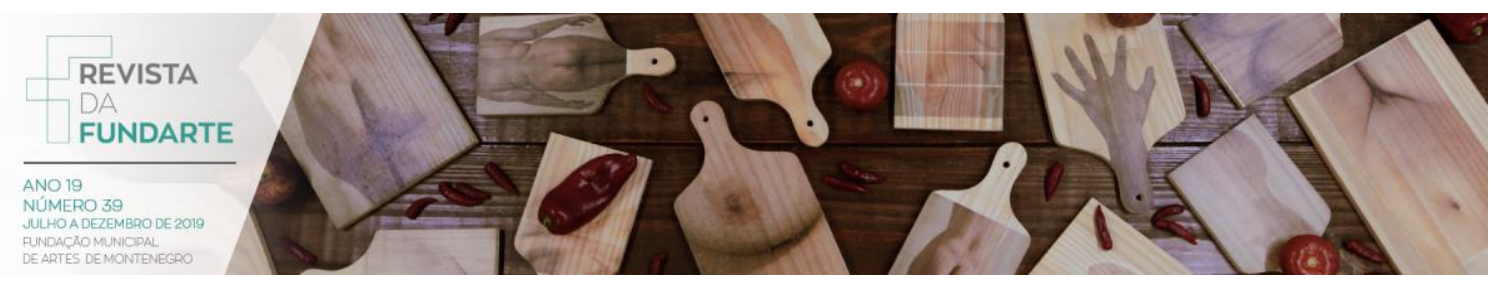

das formações acadêmicas e dos cursos que realizaram, fazendo-os, assim, professores. Para corroborar com essa ideia, Tardif afirma que

\begin{abstract}
Em seu trabalho, um professor se serve de sua cultura pessoal, que provém de sua história de vida e de sua cultura escolar anterior; ele também se apoia em certos conhecimentos disciplinares adquiridos na universidade, assim como em certos conhecimentos didáticos e pedagógicos oriundos de sua formação profissional; ele se apoia também naquilo que podemos chamar de conhecimentos curriculares veiculados pelos programas, guias e manuais escolares; ele se baseia em seu próprio saber ligado à experiência de trabalho, na experiência de certos professores e em tradições peculiares ao ofício de professor. (TARDIF, 2000, p. 13).
\end{abstract}

Os professores do BPT, além de utilizarem os conhecimentos adquiridos nas disciplinas curriculares de suas formações em nível superior, realizaram uma formação complementar, a qual permite que os mesmos adentrem no universo da arte, aprofundando-se em uma ou mais técnicas e/ou estilos de dança. O professor Tendu, por exemplo, iniciou sua formação na graduação e concomitantemente fez aulas específicas de balé, jazz e dança de salão. Além disso, o professor relata que fez cursos de formação de professores e sobre o ensino da dança.

\title{
O PLANEJAMENTO DAS AULAS DE DANÇA
}

O processo de planejar é reflexo da formação docente, ou seja, do conhecimento adquirido no período de formação em dança em espaços não formais ou na graduação. Para a professora Jeté, a preocupação de como a sua aula ocorrerá é um espelho de sua formação e a mesma, lembra que o planejamento é flexível. "O meu planejamento de aula... eu tento fechar, mas nunca consigo, por que eu vou mudando constantemente de acordo com a evolução do aluno. Então assim, fazemos um planejamento, como a gente tá fazendo agora (estávamos em uma reunião de planejamento do BPT), de acordo com aquele conteúdo que você

GLORIA, Webiston da Silva; NASCIMENTO, Diego Ebling do. Formação e propostas pedagógicas para o ensino da dança no balé popular do Tocantins. Revista da FUNDARTE. Montenegro, p.89-104, ano 19, no 39, julho/dezembro de 2019.

Disponível em: http://.seer.fundarte.rs.gov.br/index.php/RevistadaFundarte/index $>20$ de dezembro de 2019. 


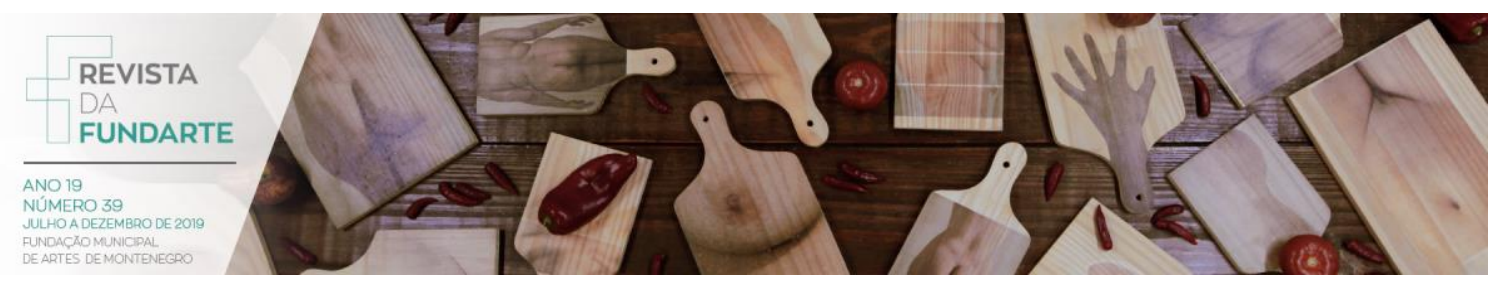

idealiza e, ao longo da apresentação do aluno naquele dia, por exemplo, eu modifico na hora minha aula".

O planejamento do balé popular acontece de forma intermodalidades, isto é, os alunos têm aulas de modalidade específica como balé e jazz e as técnicas se complementam, de acordo com o desenvolvimento e a idade dos alunos, buscando o aperfeiçoamento contínuo e a qualidade técnica e artística no decorrer do período letivo.

Professores do BPT que seguem escolas de ballet específicas, como a metodologia Cubana e Vaganova, planejam suas aulas dentro de seus respectivos métodos. Desse modo, mesmo que o BPT se proponha a ter um planejamento coletivo, se preocupando com as idades e o nível de desenvolvimento dos alunos, as aulas diferem de professor para professor, segundo suas formações específicas.

As referências dos professores se dão em torno de artistas e/ou teóricos. Alguns professores utilizam como inspiração essas referências para os processos de composição coreográficas no BPT. Os professores foram questionados sobre os autores, coreógrafos e métodos que fizeram e fazem parte do seu processo de formação, o qual se encontra no quadro 3.

\begin{tabular}{|c|c|c|c|}
\hline Professor & Método & Autor & Artista \\
\hline Plié & Método Cubano & Alicia Alonzo & \\
\hline Chassé & Indefinido & Indefinido & Jefferson Marques \\
\hline Tendu & $\begin{array}{c}\text { Método } \\
\text { Vaganova } \\
\text { Jazz Lírico } \\
\end{array}$ & Agripina Vaganova & $\begin{array}{l}\text { Erica Novak } \\
\text { Edy Wilson } \\
\text { Carla Bublitz }\end{array}$ \\
\hline Cambré & $\begin{array}{l}\text { Vaganova } \\
\text { Jazz Lírico }\end{array}$ & Agripina Vaganova & $\begin{array}{c}\text { Erica Novak } \\
\text { Rosely Rodrigues } \\
\text { Edson Santos }\end{array}$ \\
\hline Jeté & $\begin{array}{l}\text { Rudof Laban } \\
\text { Método Royal } \\
\text { Vaganova } \\
\text { Jazz Lírico }\end{array}$ & $\begin{array}{c}\text { Agripina Vaganova; Ângela } \\
\text { Ferreira; Augusto Cury; } \\
\text { Beatriz Martini Bedran } \\
\text { Heloisa Almeida; } \\
\text { Isabel Marques; } \\
\text { Jean Piaget; } \\
\text { Paola Bartolo; } \\
\text { Roberto Pereira; }\end{array}$ & Flávia Burlini \\
\hline
\end{tabular}

GLORIA, Webiston da Silva; NASCIMENTO, Diego Ebling do. Formação e propostas pedagógicas para o ensino da dança no balé popular do Tocantins. Revista da FUNDARTE. Montenegro, p.89-104, ano 19, no 39, julho/dezembro de 2019.

Disponível em: http://.seer.fundarte.rs.gov.br/index.php/RevistadaFundarte/index> 20 de dezembro de 2019. 


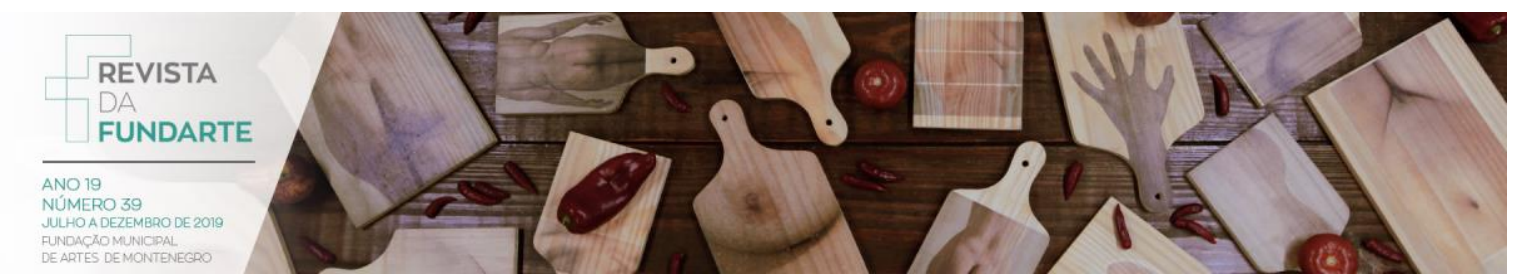

\begin{tabular}{|c|c|c|c|}
\hline & Rosana de Freitas Fachada & \\
\hline Frappé & $\begin{array}{c}\text { Método } \\
\text { Vaganova Aragão de Souza } \\
\text { Rudolf Labanches. }\end{array}$ & $\begin{array}{c}\text { Agripina Vaganova; } \\
\text { Rudolf Laban. }\end{array}$ & Marta Graham \\
\hline Ecarté & $\begin{array}{c}\text { Método } \\
\text { Vaganova } \\
\text { Método Royal }\end{array}$ & $\begin{array}{c}\text { Agripina Vaganova; } \\
\text { Leidy Emelia Escobar Sánchez }\end{array}$ & Ana Botafogo \\
\hline Arabesque & Indefinido & Indefinido & Indefinido \\
\hline
\end{tabular}

Quadro 3 - Métodos, autores e artistas estudados pelos professores do BPT. Fonte: Elaborada pelos autores.

Foi percebido que alguns professores do BPT têm pouco contato com a literatura da dança. Apenas dois professores listaram autores que não são criadores de métodos, talvez, por serem professores que possuem uma formação com características mais voltadas às práticas da dança. Por outro lado, os artistas que ministram cursos são citados em maior quantidade, tanto para os métodos utilizados para suas aulas, como para enriquecimento de repertório dos professores.

Entendendo que os autores, artistas e métodos utilizados pelos professores do BPT influenciam suas propostas pedagógicas, podemos identificar diferentes propostas de ensino. Assim, foram identificadas duas propostas: a pedagogia diretiva e a pedagogia não-diretiva.

\section{Ensino diretivo}

A pedagogia diretiva se relaciona com o método tradicional de ensino no qual o professor fala e os alunos escutam, o professor faz e os alunos repetem. Esse aspecto diretivo, por vezes, enriquece o trabalho técnico, mas, por outro lado, pode afastar os estudantes/bailarinos. Esse afastamento vai depender da abordagem e da metodologia de cada professor.

As professoras Ecarté e Chassé dizem: "Eu tenho esse método também de fazer e o aluno reproduzir, então eu pego um movimento e tento destrinchar ele, de certa forma. Eu faço de tudo para que o meu aluno consiga entender que ele tem

GLORIA, Webiston da Silva; NASCIMENTO, Diego Ebling do. Formação e propostas pedagógicas para o ensino da dança no balé popular do Tocantins. Revista da FUNDARTE. Montenegro, p.89-104, ano 19, no 39, julho/dezembro de 2019.

Disponível em: http://.seer.fundarte.rs.gov.br/index.php/RevistadaFundarte/index $>20$ de dezembro de 2019. 


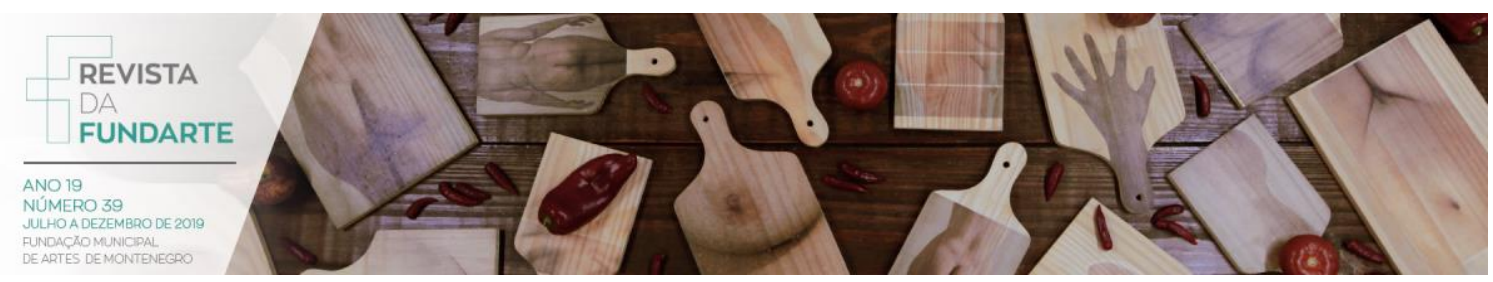

que fazer aquele movimento daquela forma" e "uso pelo semestre, eu monto uma sequência que elas fazem durante seis meses essa aula, ai eu vejo se evoluiu, se evoluiu eu passo, vamos supor, ela começa na barra aí, eu já sei que tá bom, aí elas já vão para o centro, fazendo o mesmo exercício, se ficou legal então a gente vai fazer agora na diagonal, então eu vou evoluindo, ou de três em três meses ou durante o semestre, de semestre em semestre".

Outros exemplos dessa proposta são desenvolvidos pelos professores Tendu, Cambré, Jeté, Frappé e Ecarté, que afirmaram utilizar os métodos Royal e Vaganova na dança clássica. Almeida (2015, p. 12), afirma que: O Método Vaganova, também conhecido como Balé Russo, foi criado em 1920, pela russa Agrippina Vaganova. Reúne a técnica francesa e inglesa, tendo apenas pequenas modificações como execução de passos, posturas corporais e nomenclatura. O método Royal Academy of Dance (RAD), também conhecida como "método inglês", trabalha muito as linhas corporais e a repetição do movimento na busca da perfeição técnica (ALMEIDA, 2015).

Já o professor Plié trabalha com o método cubano de ballet clássico, o qual valoriza os biotipos latinos, isto é, os movimentos são melhores desenvolvidos para os corpos da América. Esse método tem suas especificidades, bem como as outras escolas de ballet, mas não foge da linha pedagógica tradicional e diretiva. Segundo Almeida (2015, p. 12), ele "sintetiza elementos naturais da cultura de seu povo latino, através de determinados movimentos de quadris e braços, comuns às danças populares do Caribe, unindo a técnica das escolas russa, francesa, inglesa e italiana".

As atitudes dos professores que utilizam a metodologia tradicional trazem algumas características que são predominantes: a) a metodologia expositiva; b) a detenção do conhecimento somente pelo professor; c) o automatismo do ensino; d) a transmissão do conhecimento formal exclusivo à escola; e) considera o conhecimento como algo acumulativo; f) o homem/aluno é um receptor passivo de informações; g) a avaliação é uma reprodução exata do que lhe é passado para o ensino da dança no balé popular do Tocantins. Revista da FUNDARTE. Montenegro, p.89-104, ano 19, no 39, julho/dezembro de 2019.

Disponível em: http://.seer.fundarte.rs.gov.br/index.php/RevistadaFundarte/index $>20$ de dezembro de 2019. 


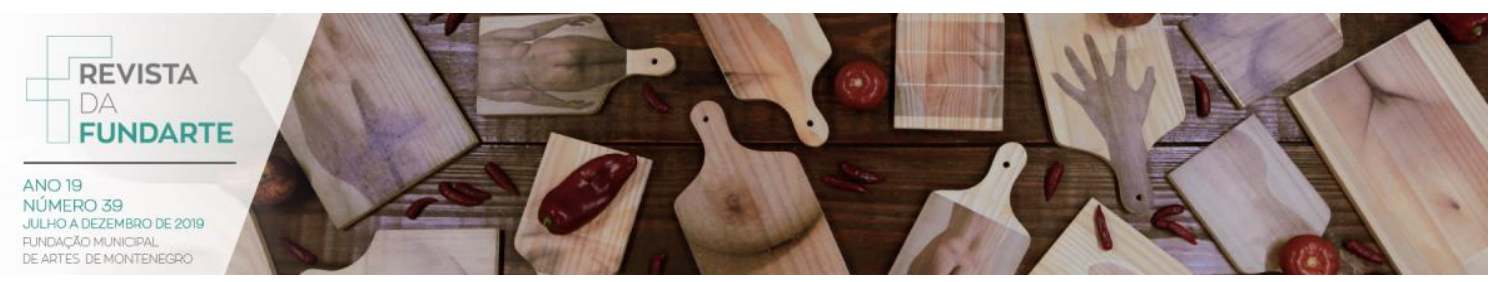

(MIZUKAMI, 1986). As aulas tradicionais primam pelo controle dos alunos e das alunas, onde deve ser predominante o silêncio para que ocorra a transmissão dos conteúdos.

Nas aulas de dança, ao invés de esperar o silêncio, o professor ditar o conteúdo e o aluno aprende, como na sala de aula convencional, torna-se corporal o controle/direcionamento: "- você tem que repetir esse movimento várias vezes para que esteja bom/perfeito!", “- essa postura está errada, é assim!” o corpo, que devia ter livre expressão, acaba por ser apenas um reprodutor de movimentos que encontra-se organizado em filas durante as aulas de dança, na tentativa de produzir corpos padrões, pois nessa concepção tudo deve estar de acordo com as concepções ou demonstrações do professor, sendo ele o centro das aulas (CORRÊA; MARTINS; SANTOS, 2017).

Uma aula de balé clássico é um exemplo de modelo tradicional de ensino da dança. A aula de balé tem como principal objetivo o aperfeiçoamento da técnica, não sobrando espaço para a participação e contribuição dos alunos. Torna-se basicamente uma reprodução do que o professor diz e/ou mostra e, o aluno tem que realizar com perfeição para que seja configurado o movimento ou expressão da técnica.

Assim, se faz necessário pensarmos em estratégias para o ensino do balé clássico que não limitem o aluno apenas a reprodução técnica dos passos. O BPT, por misturar outras estéticas de dança, como o jazz, a dança contemporânea, a dança de salão e a dança de rua, pode promover rupturas dessa lógica mecanicista da dança.

\section{Ensino não-diretivo}

A pedagogia não-diretiva e a abordagem humanista apresentam a mesma visão, ou seja, não centralizar o professor como detentor do conhecimento, mas o aponta como mediador que cria as possibilidades para a aprendizagem dos e das estudantes Suas características são: o homem está sempre em processo de construção de seus conhecimentos; o mundo está em mudança constante sendo GLORIA, Webiston da Silva; NASCIMENTO, Diego Ebling do. Formação e propostas pedagógicas para o ensino da dança no balé popular do Tocantins. Revista da FUNDARTE. Montenegro, p.89-104, ano 19, no 39, julho/dezembro de 2019.

Disponível em: http://.seer.fundarte.rs.gov.br/index.php/RevistadaFundarte/index $>20$ de dezembro de 2019. 


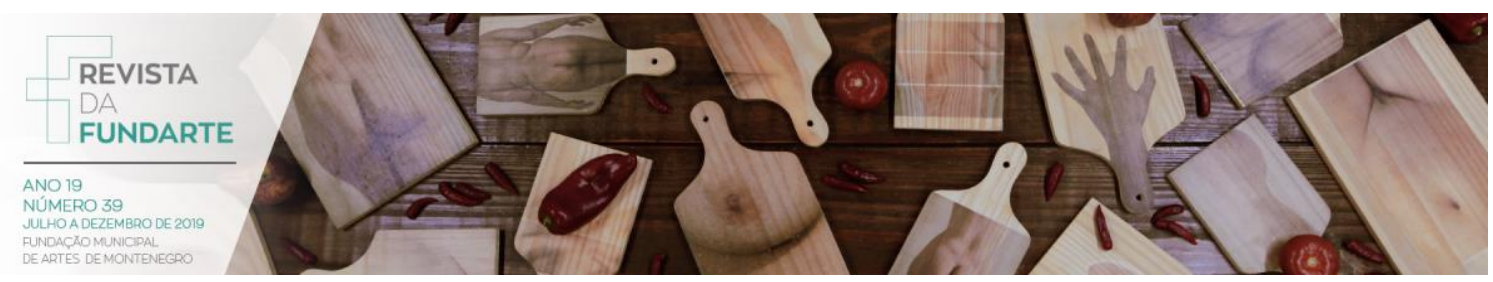

necessárias adaptações; a atenção é voltada ao aluno; a escola possibilita autonomia; a relação entre aluno e professor são mediadas por auxílios do docente, para que o estudante consiga alcançar seus objetivos; o professor busca metodologias que facilitam a aprendizagem dos alunos nas suas individualidades; a avaliação é qualitativa com demonstração de controle de aprendizagem (MIZUKAMI, 1986).

$\mathrm{Na}$ dança contemporânea e nas danças urbanas, o professor Frappé relata utilizar a composição coreográfica, quando afirma: "a gente usa imagens para compor coreografia, contato improvisação, a gente vai trabalhar com o conjunto inteiro a questão da confiança do grupo".

A professora Jeté tem como base a proposta de Rudof Laban. Ela diz que "na dança contemporânea eu gosto muito de Laban, eu uso a metodologia de Laban" essa metodologia pode ser considerada como proposta de ensino relacional.

Já a professora Arabesque utiliza-se de propostas pedagógicas lúdicas para desenvolver suas aulas, ela afirma que: "Sempre proponho atividades lúdicas, dependendo da faixa etária, eu gosto bastante de trabalhar assim na aula, por que o balé é cansativo, então no final das aulas eu costumo trabalhar algumas atividades lúdicas, para poder envolver as crianças."

Isabel Marques considera que a ludicidade nas aulas de dança consegue alcançar maiores vínculos entre os alunos.

A ludicidade da arte a que me refiro aqui certamente não está ligada ao senso comum que acredita ser o lúdico uma "brincadeira simplória de criança". A situação educacional lúdica está relacionada à criação e à transformação, brincar é criar vínculos, "a brincadeira abre a possibilidade de criar outro mundo e outro jeito de ser e de viver" (FORTUNA, 2006, p. 3, citado por MARQUES, 2011). Brincar possibilita estabelecer relações: e as relações são sempre transformadoras (FREIRE, 1982, citado por MARQUES, 2011).

Assim, se em nossas salas de aula de dança, eminentemente dançando, propiciarmos situações em que corpos possam brincar - criar vínculos estaremos também contribuindo para a educação de corpos sociais cidadãos brincantes que saibam estabelecer vínculos com os outros e com o mundo em que vivem. (MARQUES, 2011, p. 34).

GLORIA, Webiston da Silva; NASCIMENTO, Diego Ebling do. Formação e propostas pedagógicas para o ensino da dança no balé popular do Tocantins. Revista da FUNDARTE. Montenegro, p.89-104, ano 19, no 39, julho/dezembro de 2019.

Disponível em: http://.seer.fundarte.rs.gov.br/index.php/RevistadaFundarte/index $>20$ de dezembro de 2019. 


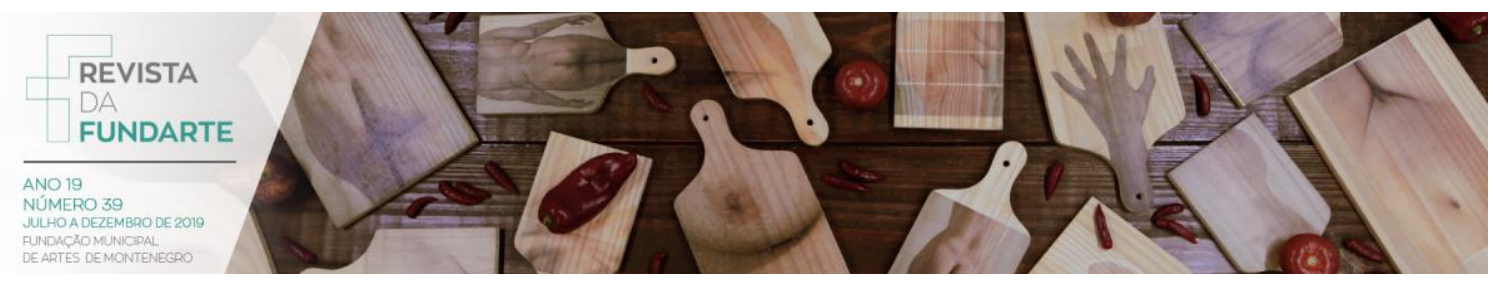

$\mathrm{Na}$ dança, a pedagogia não diretiva faz com que o professor proponha e os seus alunos criem, trazendo as características de cada indivíduo e dispensando preparações técnicas a princípio. Nesse processo a possibilidade do estudante ficar à mercê de uma aleatoriedade de movimentos desconexos ao seu cotidiano é menor. O processo criativo pode ser confundido com a improvisação, porém são distintos: a criação é algo espontâneo e consciente que se deixa fazer e pode ser sistematizada, a improvisação se dá como algo momentâneo que objetiva a desinibição nas aulas (CORRÊA; MARTINS; SANTOS, 2017).

A improvisação tem uma visão deturpada na sociedade, como se fosse qualquer coisa, porém artistas e professores de dança trazem o improviso como uma possibilidade de prática dos fundamentos teóricos construídos ao longo dos últimos séculos, principalmente, pautados na dança educativa moderna (MARQUES, 2002), o que muda a concepção do "fazer qualquer coisa", para compreender e dar significado para o movimento. Quando trabalhado em conjunto ou mediado por um professor rompe barreiras, ultrapassando a desinibição e ganhando um novo sentido, contemplando conhecimentos, resgatando e contribuindo com a história corporal dos alunos (CORRÊA; MARTINS; SANTOS, 2017).

No processo pedagógico não-diretivo o sucesso depende do repertório do aluno, uma vez que o ensino é mediado, de acordo com o que o aluno tem de conhecimento, com isso o trabalho do professor limita-se ao que o aluno tem a oferecer.

A pedagogia diretiva está bastante presente, pois a maioria dos professores se utilizam de métodos de ballet clássico para suas aulas. Como falamos anteriormente, a reprodução, a busca por movimentos e corpos padronizados são a maneira de se ministrar as aulas, porém podemos perceber que alguns professores utilizam, também, a pedagogia não-diretiva, como foi o caso dos professores Frappé e Jeté, que usam Laban para suas aulas e, a professora Arabesque, que propõe atividades lúdicas nas aulas, mesmo que ainda para descontração dos alunos, pelo estresse causado pelo tradicionalismo do Ballet.

GLORIA, Webiston da Silva; NASCIMENTO, Diego Ebling do. Formação e propostas pedagógicas para o ensino da dança no balé popular do Tocantins. Revista da FUNDARTE. Montenegro, p.89-104, ano 19, no 39, julho/dezembro de 2019.

Disponível em: http://.seer.fundarte.rs.gov.br/index.php/RevistadaFundarte/index> 20 de dezembro de 2019. 


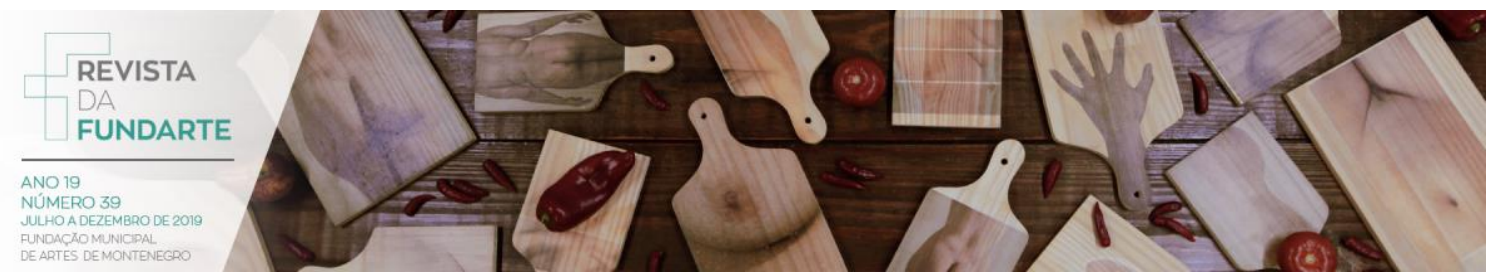

\section{CONSIDERAÇÕES FINAIS}

O BPT é um projeto que teve início no ano de 2013. A maioria dos professores que atuam nele estão desde sua fundação. Alguns professores que ingressaram recentemente já foram alunos e os professores mais antigos são considerados como referências do projeto. A entrada de novos professores no BPT indica a ampliação de entendimentos do BPT.

Notamos que os professores do BPT fizeram muitos investimentos em sua carreira. Alguns iniciaram suas práticas em dança ainda na infância ou na adolescência. A formação docente é constituída de diversas maneiras, perpassando por cursos de formação universitária, escolas e estúdios de dança, seminários e congressos, além da formação que é construída por meio da própria prática docente.

Todos os professores tiveram algum contato com a dança durante sua formação acadêmica, que se distribuíram nos cursos de Educação Física, Dança e Teatro. Com exceção de dois professores que iniciaram sua trajetória com a dança na faculdade, os demais já haviam tido experiências com a dança antes da formação inicial. Desse modo, o processo de graduação foi uma contribuição para suas formações, que já estavam em andamento.

Uma vantagem do projeto é que todos os profissionais trabalham com o que escolheram para suas carreiras docentes e recebem alunos que querem dançar, diferenciando o projeto das disciplinas de dança do currículo formal nas escolas.

Os professores do BPT fazem seus planejamentos de acordo com as turmas, idades e nivelamento técnico considerando as dificuldades e o desenvolvimento de cada aluno. Para isso, alguns professores utilizam a pedagogia diretiva por meio de propostas metodológicas de ensino desenvolvidas para o ballet clássico, que apresentam métodos estruturados para essa modalidade. Alguns professores seguem o método russo, outros o inglês e um professor se inspira no método do balé cubano.

GLORIA, Webiston da Silva; NASCIMENTO, Diego Ebling do. Formação e propostas pedagógicas para o ensino da dança no balé popular do Tocantins. Revista da FUNDARTE. Montenegro, p.89-104, ano $19, n^{\circ} 39$, julho/dezembro de 2019.

Disponível em: http://.seer.fundarte.rs.gov.br/index.php/RevistadaFundarte/index> 20 de dezembro de 2019. 


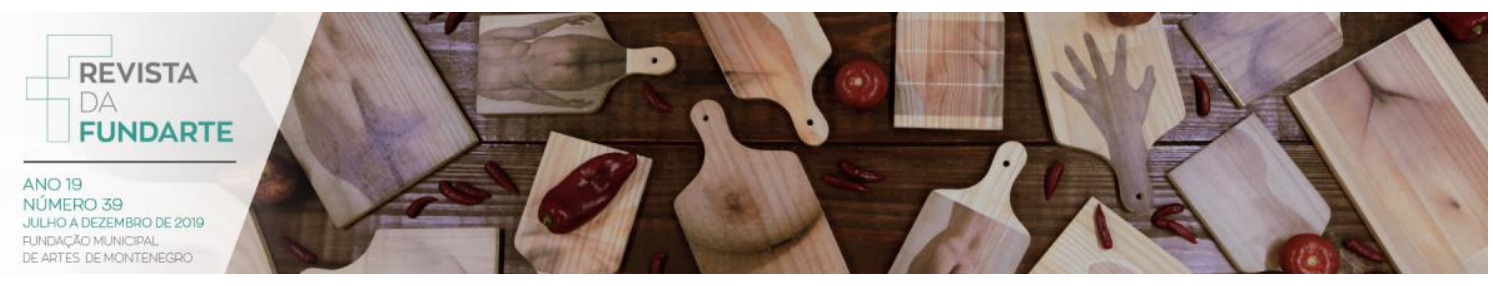

Outros professores utilizam a pedagogia não-diretiva em suas aulas. Para isso, se inspiram nas propostas Rudolf Laban, na composição coreográfica e no ensino lúdico da dança.

Percebemos que os professores Jeté e Frappé têm uma proposta metodológica predominantemente pautada na pedagogia não-diretiva. Os mesmos possuem formação acadêmica particulares, ambos são formados na área da Arte dança e teatro, respectivamente. Isso pode indicar que as formações em Arte e em Educação Física podem estar promovendo modos de pensar/fazer dança diferentes.

O BPT é o maior projeto de dança do estado do Tocantins no momento e se constitui como uma grande oportunidade para quem quer iniciar sua carreira na dança e se profissionalizar.

As aulas de diferentes modalidades, como balé clássico, dança contemporânea, jazz e dança de rua são modalidades oferecidas pelo BPT gratuitamente, com ótima qualidade e destinada à comunidade. Essa oportunidade é uma forma de acesso à dança para pessoas que não teriam condições de pagar aulas em escolas particulares, contribuindo para a formação artística, pedagógica e profissional na área da dança.

\section{Referências:}

ALMEIDA, Uriel Trindade de. LBO: um método de abordagem que respeita as singularidades corporais em um ensino contemporâneo para o balé clássico. 2015. 40 p. Monografia (Graduação em Licenciatura em Dança) - Universidade Federal de Sergipe, Campus de Laranjeira, Laranjeiras, 2015.

CORRÊA, Josiane Franken; MARTINS, lassanã; SANTOS, Vera Lúcia Bertoni. Concepções pedagógicas e o ensino de dança na escola. Revista da FUNDARTE, v. 34, n. 34, p. 31-44, 2017.

DE PINHO, M. J.; SOMMER, Márcia Regina R. G.; MARQUES, J. S. Balé Popular do Tocantins: experiência formativa em dança no cerrado brasileiro. In: SEMINÁRIO DA REDE INTERNACIONAL DE ESCOLAS CRIATIVAS - RIEC, 3., 2017, Palmas - TO. Anais... Palmas: EDUFT, 2017.

MARQUES, Isabel A. Revisitando a dança educativa moderna de Rudolf Laban. Sala Preta, v. 2, p. 276-281, 2002.

GLORIA, Webiston da Silva; NASCIMENTO, Diego Ebling do. Formação e propostas pedagógicas para o ensino da dança no balé popular do Tocantins. Revista da FUNDARTE. Montenegro, p.89-104, ano 19, no 39, julho/dezembro de 2019.

Disponível em: http://.seer.fundarte.rs.gov.br/index.php/RevistadaFundarte/index $>20$ de dezembro de 2019. 


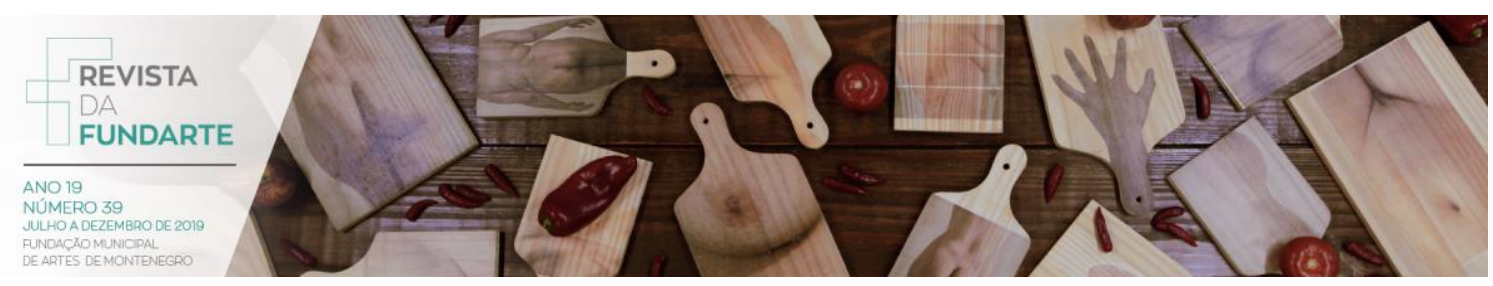

. Dançando na escola. São Paulo: Cortez, 2003.

8, n. 1, 2011.

Notas sobre o corpo e o ensino de dança. Revista Caderno Pedagógico, v.

MARTINELLI, Suselaine Serejo; BARBATO, Silviane; MITJANS, Albertina Martinez. No ensino, quem dança?: Uma análise crítica sobre a criatividade no ensino da dança no Distrito Federal. Estud. pesqui. psicol., Rio de Janeiro , v. 3, n. 2, p. 5162, jul. 2003.

Disponível em: http://pepsic.bvsalud.org/scielo.php?script=sci arttext\&pid=S1808$\underline{42812003000200004 \& \operatorname{lng}=\text { pt\&nrm=iso. }}$. Acessado em: 05 set. 2018.

MIZUKAMI, Maria da Graça Nicoletti. Ensino: as abordagens do processo. São Paulo: Editora Pedagógica e Universitária, 1986.

NUNES, Célia Maria Fernandes. Saberes docentes e formação de professores: um breve panorama da pesquisa brasileira. Educação \& Sociedade, ano XXII, ํำ 74, Abril, 2001.

TARDIF, Maurice. Saberes profissionais dos professores e conhecimentos universitários. Revista brasileira de Educação, v. 13, n. 5, p. 5-24, 2000.

TRIVIÑOS, Augusto Nibaldo Silva. Introdução à pesquisa em ciências sociais: a pesquisa qualitativa em educação. São Paulo: Atlas, 1987.

GLORIA, Webiston da Silva; NASCIMENTO, Diego Ebling do. Formação e propostas pedagógicas para o ensino da dança no balé popular do Tocantins. Revista da FUNDARTE. Montenegro, p.89-104, ano 19, no 39, julho/dezembro de 2019.

Disponível em: http://.seer.fundarte.rs.gov.br/index.php/RevistadaFundarte/index $>20$ de dezembro de 2019. 